\title{
THE ROLE OF SOMATIC TRAIT ANXIETY AND ALEXITHYMIA ON THE PHYSIOLOGICAL AND SUBJECTIVE RESPONSES TO EMOTIONAL STIMULI
}

\section{Filipa Barros ${ }^{a, b, c^{*}}$, Cláudia Figueiredo ${ }^{d}$ Susana Brás ${ }^{e}$, João M. Carvalhoe \& Sandra C. Soares ${ }^{a, b, c}$}

a Center for Health Technology and Services Research CINTESIS.UA, Department of Education and Psychology, Aveiro, Portugal

b William James Center for Research (WJCR), Department of Education and Psychology, University of Aveiro, Aveiro, Portugal

${ }^{c}$ Department of Education and Psychology, University of Aveiro, Aveiro, Portugal

d GOVCOPP, University of Aveiro, Aveiro, Portugal

e Department of Electronics, Telecommunication and Informatics (DETI)/Institute of Electronics and Informatics Engineering (IEETA), University of Aveiro, Portugal

Corresponding author: fmbarros@ua.pt

\section{Background}

- Trait anxiety is a multidimensional response that determines the susceptibility to experience anxiety in daily life ${ }^{1}$.

- The pattern of somatic anxiety generally presented by an individual, the Somatic Trait Anxiety (STA), may be important to predict the physiological, subjective and behavioral response towards daily situations ${ }^{2,3}$.

- Alexithymia (ALE) is a personality trait reflecting difficulties in identifying and reporting feelings and has been associated with anxiety disorders, emotion regulation difficulties, and with the physiological reactivity to emotional stimuli4,5,6,7.

\section{Method}

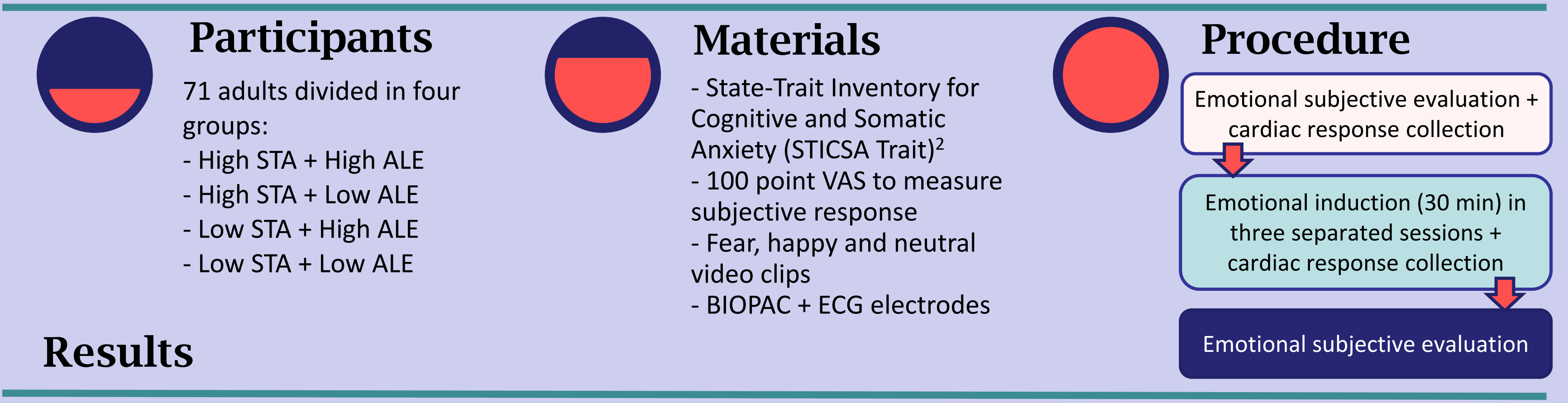

\section{Percentage of HF power (HRV)}

Fear induction

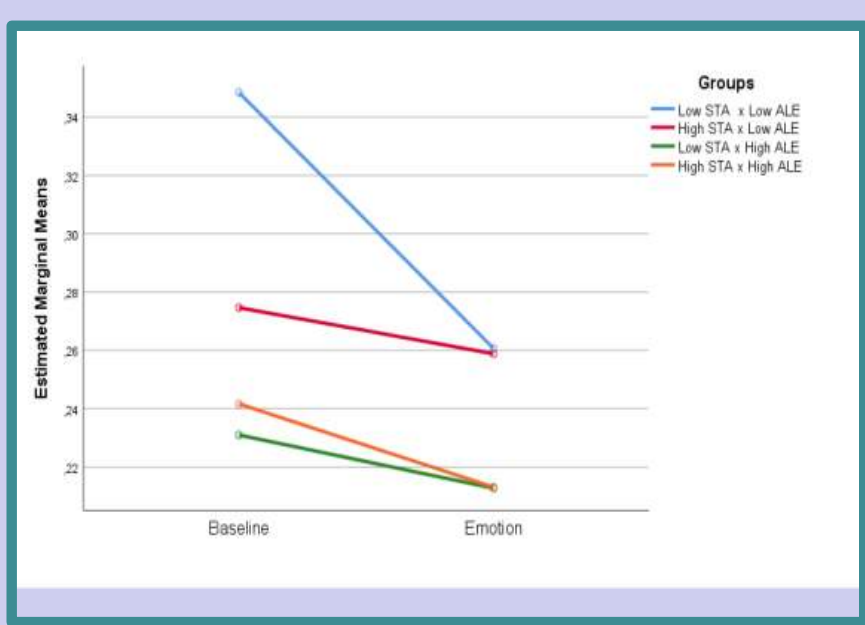

Neutral condition

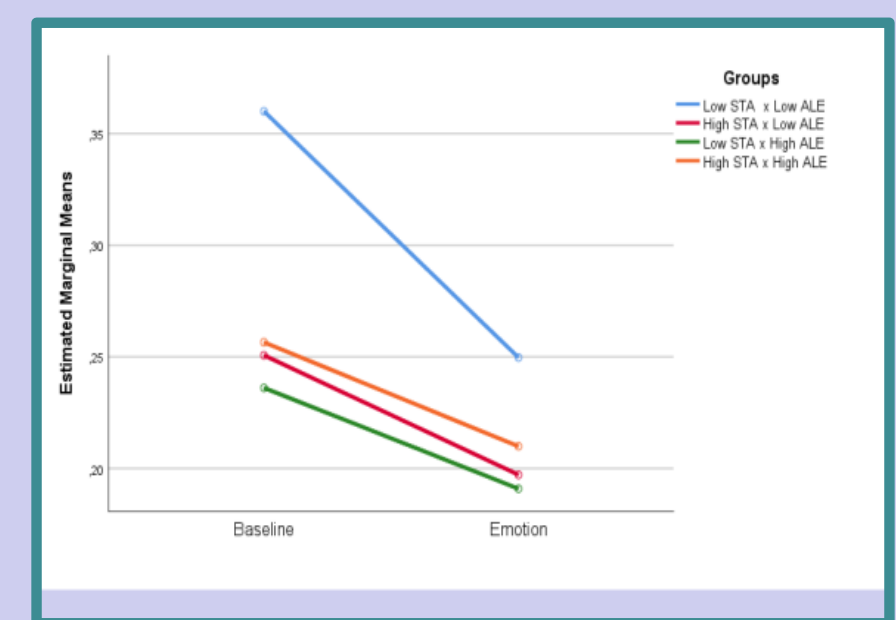

Aim

To analyze the differential association of trait somatic anxiety and alexithymia with objective and subjective emotional responses towards emotionally intense situations

- A repeated measures ANOVA was performed to evaluate differences between the four groups;

- Differences regarding emotional subjective evaluation did not reach significance, $p<.05$;

- In fear condition, individuals with lower ALE and STA presented significantly higher HF power \% in comparison with the two groups with high ALE in both baseline and emotional induction, suggesting decreased parasympathetic control in groups with high ALE;

- In happy and neutral condition, individuals with lower ALE and STA presented higher HF power \% in comparison with the other three groups.

These findings highlight the distinct emotional information obtained from subjective or psychophysiological measures, strengthening the importance of assessing these two traits for prognostic and intervention planning. 